\title{
PRODUÇÃO DE MUDAS PRÉ-BROTADAS DE CANA-DE-AÇÚCAR EM FUNÇÃO DE DIFERENTES SUBSTRATOS
}

Luis Eduardo Vieira Pinto ${ }^{1,3}$, Thadeu Henrique Novais Spósito ${ }^{2,3}$, Angela Madalena Marchizelli Godinho $^{1,3}$, Fernando Bernardo Martins ${ }^{1}$

${ }^{1}$ Universidade do Oeste Paulista - UNOESTE, Programa de Pós-Graduação em Agronomia, Presidente Prudente,SP. ${ }^{2}$ Universidade Estadual Paulista, FEIS/ Programa de Pós-Graduação em Agronomia, Ilha Solteira, SP. ${ }^{3}$ Centro Paula Souza - ETEC 032, Presidente Prudente, SP. E-mail: levp@unoeste.br

\section{RESUMO}

A utilização de mudas pré-brotadas (MPB) é direcionada para aumentar a eficiência e os ganhos econômicos na implantação de viveiros. O objetivo deste estudo foi avaliar a influência de diferentes concentrações de substratos agrícolas para a produção de MPB de cana-de-açúcar, bem como avaliar o desenvolvimento inicial destas mudas. Utilizou-se o delineamento experimental inteiramente casualizado, contendo 4 tratamentos (substratos), com 6 repetições e 1 planta por unidade experimental. Fontes orgânicas de fósforo $(P)$, como a torta de filtro, tem papel fundamental para a vida de microrganismos, aumentando a CTC do solo e a mobilidade de P no solo. A adição da torta de filtro aos tratamentos 3 e 4 pode ter disponibilizado ao meio, nutrientes essenciais para o desenvolvimento dos minirrebolos, promovendo uma boa aeração e retenção de umidade. $\mathrm{O}$ uso da torta de filtro em mistura com outros substratos pode ser utilizado para a produção de MPB de cana-de-açúcar.

Palavras-chave: Plantio; Torta de filtro; Compostagem; Tolete; Mini rebolo.

\section{SEEDLING PRODUCTION OF PRE-SPROUTED CANE SUGAR IN DIFFERENT FUNCTION SUBSTRATES}

\begin{abstract}
The use of pre-sprouted seedlings (MPB) is intended to increase efficiency and economic gains in the implementation of nurseries. The aim of this study was to evaluate the influence of different concentrations of agricultural substrates for the production of MPB sugarcane and evaluate the initial development of these seedlings. We used a completely randomized design, containing 4 treatments (substrates) with 6 replicates and one plant each. organic sources of phosphorus (P) as the filter cake, has a fundamental role in the life of microorganisms, increasing soil CEC and mobility of $P$ in the soil. The addition of filter cake to treatments 3 and 4 may be provided in half, essential nutrients for the development of minirrebolos, promoting good aeration and moisture retention. The use of filter cake in admixture with other substrates may be used for the production of MPB sugarcane.
\end{abstract}

Keywords: Planting; Filter cake; Composting; Tolete; Mini grinding wheel. 


\section{INTRODUÇÃO}

Segundo Segato et. al., (2006), a cana-de-açúcar é originária da Nova-Guiné e foi levada para o sul da Ásia, de onde foi disseminada para várias outras regiões. Ela é uma poácea semiperene, que possibilita vários cortes sem necessidade de replantio e expressa desenvolvimento satisfatório em solos aerados, bem drenados, o que denota que ela exige solos com profundidades acima de um metro. Em lavouras comerciais, a propagação da cana-de-açúcar é realizada vegetativamente, ou seja, de forma assexuada a partir dos toletes, que é parte da planta contendo gemas, reservas nutricionais, hídricas e hormonais (LANDELL et al., 2012).

A partir do plantio mecanizado dos canaviais começam a aparecer problemas relacionado as falhas nas linhas de plantio. Havendo condições favoráveis, a gema se torna ativa e ocorre o crescimento e desenvolvimento devido à presença de reservas nutricionais, ativação de enzimas e reguladores de crescimento (DILLEWINJ, 1952). Ou seja, pode ser que a gema brote e desenvolvase uma planta, e pode ser que a gema não brote caso não encontre condições favoráveis, acarretando em falhas no canavial. Percebendo esse problema o Instituto Agronômico de Campinas (IAC) vem desenvolvendo um novo método de plantio, que visa à multiplicação de mudas pré-brotadas (MPB) de cana-de-açúcar oriunda de gemas individualizadas e a diminuição de colmos utilizados no plantio, visto que essa economia de matéria prima será direcionada para indústria viabilizando ainda mais a produtividade e ganhos econômicos (DINARDO; VASCONCELOS; LANDELL, 2010).

Mudas pré-brotadas (MPB) de cana-de-açúcar é um sistema de multiplicação que vem contribuindo para a produção rápida de mudas, associando elevado padrão de fitossanidade, vigor e uniformidade. Esse sistema aumenta a uniformidade nas linhas de plantio, reduz o número de falhas, reduz o volume de mudas, diminui o risco de difusão de pragas e doenças e acelera a introdução de tecnologias varietais na área agrícola (LANDELL et al., 2012). A utilização dessa tecnologia pode ser empregada na implantação de viveiros, replantio de áreas comerciais e renovação e expansão de áreas de cana-de-açúcar (TONIELI et al., 2012).

A obtenção de toda e qualquer tipo de mudas de qualidade ainda representa um desafio, pois depende do uso de substratos com boas condições sanitárias e com propriedades físicoquímicas que favoreçam o crescimento e o desenvolvimento inicial das plantas (SMIRDELE et al., 2001). Segundo Ramos et al., (2000) o substrato é definido como meio físico natural ou sintético, onde se desenvolvem as raízes das plantas. Também pode ser definido como qualquer material usado com a finalidade de servir de base para o desenvolvimento de uma planta até a sua transferência para o viveiro ou para a área de produção. Pode ser compreendido não apenas como suporte físico, mas também como fornecedor de nutrientes para a muda em formação. Dessa forma, um bom substrato é aquele que proporciona condições adequadas à germinação e ao desenvolvimento do sistema radicular da muda em formação.

O substrato é um dos fatores de maior influência na formação e produção de mudas, podendo apresentar vantagens, mas também desvantagens, em função, principalmente, da espécie vegetal em que se está trabalhando, por isso vem sendo estudado intensamente para obter-se melhores condições de desenvolvimento e formação de mudas de qualidade (MENEZES JÚNIOR e FERNANDES, 1999).

Os substratos podem ser diferenciados como orgânicos ou minerais, quimicamente ativos ou inertes. Os materiais orgânicos têm origem em resíduos vegetais, sujeitos à decomposição e, por isso, são mais ou menos quimicamente ativos devido aos sítios de troca iônica, podendo adsorver nutrientes do meio ou liberá-los a eles. Entretanto, a maioria dos substratos minerais é quimicamente inativa ou inerte, com exceção de alguns materiais que possuem alta capacidade de troca de cátions, como a vermiculita. Os materiais orgânicos mais comumente utilizados no cultivo de plantas podem ser exemplificados com: turfa, cascas de árvores (sobretudo pínus), fibra de 
coco, casca de arroz carbonizada, outras fibras e cascas. As matérias-primas minerais podem ser: vermiculita, perlita, espuma fenólica, lã de rocha, argila expandida (ZORZETO, 2011).

A torta de filtro é um subproduto da indústria canavieira resultante da purificação do caldo e baixíssimo custo. A torta de filtro, quando incorporada ao solo, em doses elevadas apresenta propriedades corretivas da acidez do solo, devido aos efeitos quelantes da matéria orgânica sobre o alumínio (ROSSETO e DIAS, 2005). De acordo com Santos et al. (2010) o fósforo existente na torta de filtro é orgânico, sendo que a liberação do mesmo e do nitrogênio se dão gradativamente, por mineralização e por ataque de microrganismos no solo. Sendo assim a torta de filtro apresenta-se como um subproduto que além de fornecer nutrientes e matéria orgânica para o sistema pode também reduzir os custos de produção dentro dos viveiros produtores, características desejadas para a produção de um substrato de qualidade.

O objetivo deste estudo foi analisar a influência de diferentes tipos de substratos agrícolas para a produção de mudas pré-brotadas de cana-de-açúcar, avaliando o desenvolvimento da parte aérea e sistema radicular das mudas produzidas, tendo como hipótese que a adição da torta de filtro junto a um substrato comercial poderá melhorar as condições para o desenvolvimento das mudas pré-brotadas de cana-de-açúcar.

\section{METODOLOGIA}

O experimento foi conduzido no município de Presidente Prudente/SP, sua implantação foi realizada no dia 01 de abril de 2015. Utilizou-se o delineamento experimental inteiramente casualizado, contendo 4 tratamentos (substratos), com 6 repetições e 1 planta por unidade experimental. Os tratamentos utilizados foram: T1 (Testemunha "Substrato comercial da Marca Bioplant "); T2 (50\% Substrato comercial + 50\% Terra de subsolo v/v); T3 (50\% Terra de subsolo + $50 \%$ Torta de filtro v/v); T4 (50\% Substrato comercial $+50 \%$ Torta de filtro v/v). O substrato comercial foi definido como tratamento testemunha no experimento por se tratar de uma prática comum adotada nos viveiros de mudas de cana-de-açúcar. $O$ uso desse tipo de substrato possui em sua composição uma mistura de casca de pinus e fibra de coco que propiciam uma ótima relação física, espaços de aeração, capacidade de retenção de água, CTC (capacidade de troca catiônica) e, consequentemente, bom desenvolvimento da raiz. Além do fator padronização, as unidades industriais optam pelo uso de substratos comerciais na produção de suas mudas pelo fato de que esse tipo de substrato é isento de microrganismos patogênicos para as plantas tais como fungos, bactérias, nematoides e ervas daninhas, fatos esses que normalmente não se conseguem obter quando da utilização de solo para a produção de mudas pré-brotadas. A terra de subsolo utilizada para o preparo do substrato no experimento é oriunda da área agrícola da universidade do Oeste Paulista, cujo o solo é caracterizado como Argissolo Vermelho distroférrico (EMBRAPA, 2006), com características de apresentarem frequentemente, mas não exclusivamente, baixa atividade da argila (CTC), podendo ser alíticos (altos teores de alumínio), baixa saturação de bases, sendo normalmente ácidos e de baixa a média fertilidade. A caracterização química do solo utilizado no experimento segundo metodologia proposta por Raij et al. (2001), na profundidade $0-0,2 \mathrm{~m}$ e os valores obtidos foram: matéria orgânica de $5,1 \mathrm{~g} \mathrm{dm}^{-3}$; $\mathrm{pH}\left(\mathrm{CaCl}_{2}\right)$ 5,4; $\mathrm{P}$ (resina) 9,6 mg dm${ }^{-3}$; S 3,1 mg dm${ }^{-3} \mathrm{H}+\mathrm{Al}$ e $\mathrm{K}$, Ca e Mg trocáveis de 11,6; 1,2; 12,5 e 6,5 mmolc $\mathrm{dm}^{-3}$. De acordo com Paranhos (1987) e Vitti et al., (2006) a composição média de 100 gramas de torta de filtro oriunda do processo sucroalcooleiro possui $8,04 \%$ de $C ; 0,28 \% \mathrm{~N} ; 0,53 \mathrm{mg}$ P - Orgânico; 1,18 mg P - inorgânico; 1,70 mg P - total; 56,64 mg K; 76,9 mg Mg; 16,90\% matéria orgânica; 77,77\% água livre; 3 ppm B; 11 - 15 ppm Cu; 138 - 196 ppm Mn; 20 - 33 ppm Zn; 0,3 ppm Co e 3.500 ppm Fe.

Para a execução do ensaio e produção das mudas, utilizou-se a variedade de cana-deaçúcar RB 867515. As mudas foram obtidas a partir do corte de $3 \mathrm{~cm}$ da região nodal da cana-deaçúcar, para assim produzir os minirrebolos (pedaço do colmo constituído da gema da cana-de- 
açúcar que dão origem as mudas). Os minirrebolos após cortados eram lavados, submetidos a um tratamento térmico de imersão em água à $52^{\circ} \mathrm{C}$ durante o período de 30 minutos, antes de semear os minirrebolos nos tubetes com os substratos, foi aplicado um fertilizante para indução de formação de raízes, esse fertilizante foi aplicado semanalmente durante 4 semanas.

Para o preparo dos substratos utilizou-se um homogeneizador modelo HM-250 da marca IRBI Máquinas e Equipamentos Ltda. As proporções volume/volume de cada material eram misturados de acordo com cada tratamento e homogeneizados durante um período de 5 minutos. Após o preparo dos substratos os tubetes eram preenchidos e realizados o plantio dos minirrebolos. Os tubetes eram dispostos sobre um suporte de madeira e tela construído especificamente para o experimento, com elevação de $1 \mathrm{~m}$ do solo, e acondicionadas em estufa. As brotações das mudas ocorreram no sétimo dia após o preparo dos tubetes sendo que, a irrigação foi realizada diariamente em três períodos distintos do dia.

A partir do 160 dia até o final do experimento as mudas foram retiradas da estufa e deixadas protegidas apenas por uma tela sombrite, sendo irrigadas diariamente 3 vezes ao dia até o $26^{\circ}$ dia. A partir do $27^{\circ}$ dia a irrigação foi reduzida para 1 vez ao dia e colocadas a pleno sol para a fase de "rustificação", que consiste na diminuição do número de irrigações e/ou da quantidade de água aplicada em cada irrigação, tendo como consequência um aumento na capacidade de estabelecimento das mudas no campo, sob condições adversas (DAVIDE e FARIA, 2008)

Após serem mantidas em desenvolvimento por 50 dias nessas condições as amostras de cada tratamento foram coletadas e levadas para o laboratório para a realização das análises de comprimento da parte aérea, massa seca da raiz e massa seca da parte aérea. O comprimento da parte aérea foi realizado utilizando uma fita métrica aprovada e homologada pelo Inmetro (Instituto Nacional de Metrologia, Qualidade e Tecnologia). Para a determinação da massa seca da raiz e parte aérea foi utilizado a metodologia do FMO (Forno Microondas) de acordo com metodologia descrita por Lacerda (2009). Todos os dados foram submetidos à análise de variância (ANOVA, $p<0,05)$ e ao teste de comparação de médias Tukey $(p<0,05)$, segundo Silva $(2011)$.

\section{RESULTADOS}

A partir dos resultados expressos na tabela 1 observa-se que para a variável MSPA (massa seca da parte aérea) o tratamento 2 com o uso de (50\% Substrato comercial $+50 \%$ Terra de subsolo $\mathrm{v} / \mathrm{v}$ ) teve seu desenvolvimento inferior a todos os demais tratamentos analisados no experimento. Já quando analisando a variável MSR (massa seca da raiz), nota-se que o efeito é contrário e o tratamento 2 proporcionou um maior ganho de massa no sistema radicular das mudas produzidas. Para a variável CPA (comprimento da parte aérea), nota-se que não houve diferença estatística significativa entre os tratamentos.

Tabela 1. Resultados das análises estatísticas das variáveis analisadas "MSPA (massa seca da parte aérea), MSR (massa seca da raiz) e CPA (comprimento da parte aérea)" em relação aos substratos utilizados no experimento.

\begin{tabular}{cccc}
\hline TRATAMENTO & MSPA $(\mathrm{g})$ & MSR $(\mathrm{g})$ & CPA $(\mathrm{cm})$ \\
\hline T1 & $0,78 \mathrm{a}$ & $0,16 \mathrm{~b}$ & $10,00 \mathrm{a}$ \\
T2 & $0,14 \mathrm{~b}$ & $0,67 \mathrm{a}$ & $10,58 \mathrm{a}$ \\
T3 & $0,64 \mathrm{a}$ & $0,18 \mathrm{~b}$ & $8,42 \mathrm{a}$ \\
T4 & $0,67 \mathrm{a}$ & $0,19 \mathrm{~b}$ & $8,75 \mathrm{a}$ \\
\hline F & $10,00^{* *}$ & $22,53^{* *}$ & $3,04^{\mathrm{ns}}$ \\
\hline
\end{tabular}

Médias seguidas por letras iguais na coluna não diferem entre si pelo teste de Tukey a $5 \%{ }^{* *}$ significativo a nível de 1 e $5 \%$ de probabilidade; ${ }^{*}$ significativo ao nível de $5 \%$ de probabilidade; ns = não significativo.

$\mathrm{T} 1=100 \%$ Substrato comercial; $\mathrm{T} 2=50 \%$ Substrato comercial $+50 \%$ Terra de subsolo; $\mathrm{T} 3=50 \%$ Torta de Filtro $+50 \%$ Terra de subsolo; $\mathrm{T} 4=50 \%$ Torta de Filtro $+50 \%$ Substrato comercial. 


\section{DISCUSSÃO}

Os resultados da variável MSR (massa seca da raiz) talvez possa ser justificado, por um fator conhecido como "efeito bonsai", de acordo com Creste (2016) o desenvolvimento do sistema radicular das plantas é menor quando a mesma está sendo produzida em local com elevado teor de nutrientes e matéria orgânica, como acontece comumente na adubação realizada em covas. Dessa forma a planta não vê a necessidade de ampliar o seu sistema radicular para realizar a interceptação de nutrientes, pois os mesmos estão sendo disponibilizados de maneira mais acessível para as raízes. O autor ainda afirma que mesmo nesse tipo de situação poderá haver o crescimento normal das raízes quando não houver nas camadas superiores de solo boa disponibilidade hídrica. Rossetto e Dias (2005) afirmam que por se tratar de um material orgânico, a torta de filtro mostra elevada capacidade de retenção de água.

Foi observado que os tratamentos com a torta de filtro (T3 e T4) foram significativamente semelhantes ao tratamento com substrato comercial (T1). O uso da torta de filtro na composição dos tratamentos T3 e T4 pode ter disponibilizado para o sistema nutrientes essenciais para o desenvolvimento dos minirrebolos além de uma boa aeração e retenção de umidade. Segundo Nunes Júnior (2005) a torta de filtro, composto basicamente orgânico, tem composição química variável e apresenta altos teores de matéria orgânica, fósforo, nitrogênio, cálcio e possui, ainda, teores consideráveis de potássio, magnésio e expressivas quantidades de $\mathrm{Fe}, \mathrm{Mn}, \mathrm{Zn}$ e $\mathrm{Cu}$.

A utilização da torta de filtro como uma alternativa de material orgânico para produção de mudas de hortaliças é uma prática bastante recomendada, pois, aumenta o fornecimento de nutrientes essenciais ao desenvolvimento da planta e melhora a qualidade das propriedades físicas, químicas, e biológicas do solo ou do substrato no qual está sendo produzido (SANTOS et al., 2005).

O uso da torta de filtro para a produção de substrato ainda poderia auxiliar para um melhor desempenho da planta a campo, pois o uso de fontes orgânicas de $\mathrm{P}$ tem papel fundamental para a vida de microrganismos, aumentando a capacidade de troca catiônica (CTC) e a mobilidade de $P$ no solo (ALMEIDA, 2002).

O fósforo $(P)$ é um elemento encontrado de forma abundante na torta de filtro e de acordo com Hoppo, Elliot e Reuter (1996) é crucial no metabolismo das plantas, desempenhando papel importante na transferência de energia da célula, na respiração e na fotossíntese. É também componente estrutural dos ácidos nucléicos de genes e cromossomos, assim como de muitas coenzimas, fosfoproteínas e fosfolipídeos. As limitações na disponibilidade de $\mathrm{P}$ no início do ciclo vegetativo podem resultar em restrições no desenvolvimento, das quais a planta não se recupera posteriormente, mesmo aumentando o suprimento de $\mathrm{P}$ a níveis adequados. $\mathrm{O}$ suprimento adequado de $\mathrm{P}$ é, pois, essencial desde os estádios iniciais de crescimento da planta.

Quando estudou o uso da torta de filtro curtida como substrato agrícola para produção de mudas de pepino, tomate e repolho, Santos et al., (2005) concluiu que a torta de filtro possui grande potencial para produção de mudas olerícolas.

Segundo Rossetto e Dias (2005) para cada tonelada de cana moída, são produzidos de 30 $\mathrm{kg}$ a $40 \mathrm{~kg}$ de torta de filtro. Sendo assim o seu uso viabilizaria o processo de produção de mudas pré-brotadas nos viveiros das usinas, pois como é produzida de forma abundante sua mistura junto aos substratos comerciais poderiam reduzir os custos de produção das mudas.

\section{CONCLUSÃO}

O uso da torta de filtro para produção de mudas pré-brotadas de cana-de-açúcar é uma prática viável para serem combinadas com substratos do tipo solo e do tipo agrícola (comercial), visto que o seu uso não influencia no desenvolvimento das mudas quando comparadas ao uso de substrato agrícola puro (T1). 


\section{REFERENCIAS}

ALMEIDA, R. S. Identificação e caracterização de genes de transportadores de fosfato em cana-deaçúcar (Saccharum spp.). 2002. 90 f. Dissertação (Mestrado em Ciências) - Escola Superior de Agricultura "Luiz de Queiroz", Universidade de São Paulo, Piracicaba, 2002.

CRESTE, J. E. Nutrição de Plantas. 2016. Presidente Prudente. 1 p. Notas de aula.

DAVIDE, A. C.; FARIA, J. M. R. Viveiros Florestais. In: Davide, A. C.; Silva, E. A. A. Produção de sementes e mudas de espécies florestais. 1. ed. Lavras: UFLA, 2008.

DILLEWIJN, V.C. Botanica da cana-de-açúcar. Waltham: The Chronica Botanica, 1952.

DINARDO-MIRANDA L. L.; VASCONCELOS, A. C. M.; LANDELL, M. G. A. Cana-de-Açúcar. Campinas. Instituto Agronômico de Campinas, 2010.

EMBRAPA. Centro Nacional de Pesquisa de Solos. Sistema Brasileiro de Classificação de Solos. 2 ed. Rio de Janeiro: Embrapa Solos, 2006.

hOFFMANN, A.; NACHTIGAL, J. C.; ROSSAL, P. A. L.; CASTRO, A. M.; FACHINELLO, J. C.; PAULETTO, E. A. Influência do substrato sobre o enraizamento de estacas semilenhosas de figueira e araçaizeiro. Revista Brasileira de Fruticultura, Cruz das Almas, v. 16, n. 1, p. 302-307, abr. 1994.

HOPPO, S.D.; ELLIOT, D.E.; REUTER, D.J. Plant tests for diagnosing phosphorus deficiency in barley (Hordeum vulgare L.). Jornal Australiano de Agricultura Experimental, v.39, p.857-872, 1999. https://doi.org/10.1071/EA99029

LACERDA, M.J.R.; FREITAS, K.R.; SILVA, J.W. Determinação da matéria seca de forrageiras pelos métodos de microondas e convencional. Revista Biociência, v.25, n.3, p.185-190, 2009.

LANDELL, M. G. A.; CAMPANA, M. P.; FIGUEIREDO, P.; XAVIER, M. A.; ANJOS, I. A.; DINARDOMIRANDA, L. L.; SCARPARI, M. S.; GARCIA, J. C.; BIDÓIA, M. A. P.; SILVA, D. N.; MENDONÇA, JR; KATHAK, R. A.; CAMPOS, M. F.; BRANCALIÃO, S. R.; PETRI, R. H.; MIGUEL, P. E. M. Sistema de multiplicação de muda de cana de açúcar com o uso de mudas pré-brotadas (MPB) oriundas de gemas individualizadas. IAC - Instituto Agronômico de Campinas, 2012; Documento 109.

MENEZES JÚNIOR, F. O. G.; FERNANDES, H. S. Efeitos de substratos formulados com esterco de curral e substratos comerciais na produção de mudas de alface. Revista Científica Rural, Bagé, v. 4, n. 2, p. 15-23, 1999.

NUNES JÚNIOR, D. O insumo torta de filtro. IDEA News, Ribeirão Preto, 2005.

PARANHOS, S. B. (Coord.). Cana-de-açúcar: cultivo e utilização. Campinas: Fundação Cargill, 1987.

RAMOS, A. B.; PEIXOTO, J. R.; MELO, B. de. Efeito da composição de substratos no desenvolvimento de mudas de maracujazeiro-amarelo (Passiflora edulis Sims $f$. flavicarpa Deneger). In: CONGRESSO BRASILERIO DE FRUTICULTURA, 13., 2000, Fortaleza. Anais... Fortaleza: SBF, 2000. CD-ROM. 
ROSSETO, R.; DIAS, F. L. F. Nutrição e adubação da cana-de-açúcar: indagações e reflexões. Informações Agronômicas, Piracicaba, n. 110, p. 6-11, 2005.

SANTOS, D. H.; TIRITAN, C. S.; FOLONI, J. S. S.; FABRIS, L. B. Produtividade de cana-de-açúcar sob adubação com torta de filtro enriquecida com fosfato solúvel. Pesquisa Agropecuária Tropical, Goiânia, v.40, n.4, p.454-461, 2010. https://doi.org/10.5216/pat.v40i4.7272

SANTOS, A. C. P.; BALDOTO, P. V.; MARQUES, P. A. A.; DOMINGUES, W. L.; PEREIRA, H. L. Utilização de torta de filtro como substrato para a produção de mudas de hortaliças. Colloquium Agrariae, v. 1, n.2, dez. 2005, p. 1-5. https://doi.org/10.5747/ca.2005.v01.n2.a007

SEGATO, S. V. et al. Atualização em produção de cana-de-açúcar. Piracicaba: CP 2, 2006.

SILVA, F. de A. S. Assistat. Versão 7.6 beta (2011). Disponível em http://www.assistat.com/indexp.html.

SMIDERLE, O. S.; MINAMI, K. Emergência e vigor de plântulas de goiabeira em diferentes substratos. Revista Científica Rural, Bagé, v. 6, n. 1, p. 38-45, 2001.

TONIELI AE. PAIXÃO ACS, VANZELLA CA, ORTOLAN MCA, SCCHIERI MS, BISSON O. Sistema de produção de Mudas MPB - Mudas pré brotadas. Revista canavieiros, ed. Carla Rossini Novembro 2012; p. 24.

VITTI, G. C.; OLIVEIRA, D. B. de; QUINTINO, T. A. Micronutrientes na cultura da cana-de-açúcar. In: SEGATO, S. V. et al. (Org.). Atualização em produção de cana-de-açúcar. Piracicaba: CP 2, 2006. p. 121-138.

ZORZETO, T. Q. Caracterização física e química de substratos para plantas e sua avaliação no rendimento do morangueiro (Fragaria $\chi$ ananassa Duch.) 110 p. Dissertação (Mestrado em Agricultura tropical e subtropical) Instituto Agronômico de Campinas - IAC, Campinas, 2011. 